\title{
Attention deficit hyperactivity disorder in adulthood
}

\section{B Toone}

\section{Attention deficit disorder may persist into adult life and have a genetic basis}

A behavioural syndrome of childhood characterised by overactivity, excitability, and explosive behaviour has been recognised since the turn of the last century and is now thought to be, at certain ages, the most common disorder of childhood. ${ }^{1}$ The disorder is now recognised in the terminology of ICD- $10^{2}$ as "hyperkinetic disorder", and in DSM-IV ${ }^{3}$ as "attention deficit hyperactivity disorder" (AD/HD). The cardinal features of overactivity and impaired attention should be pervasive-that is, evident in more than one situation, and observable before the age of six (ICD-10) or seven years (DSMIV), though they are usually evident well before that. DSM-IV subclassifies $\mathrm{AD} / \mathrm{HD}$ into predominantly inattentive, predominantly hyperactive-impulsive, and combined subtypes; ICD-10 insists on the presence of both inattention and hyperactivity for a diagnosis of hyperkinetic disorder.

\section{EPIDEMIOLOGY}

The prevalence varies according to which set of diagnostic criteria is used, DSM-IV or the more restrictive ICD-10. Using the latter, prevalence in the United Kingdom is $1.5 \%$ among seven year old boys in British inner cities ${ }^{4}$; in the USA using DSM-IV criteria, this may rise as high as $9.5 \% .^{5}$ Sex differences are far more consistently reported, and boys regularly exceed girls in a ratio of 2.5:1. There is a substantial comorbidity with conduct disorder and oppositional deviant disorder, although the two conditions are not readily separated, and with reading disorder, obsessive compulsive disorder, multiple tic disorder, and Tourette's syndrome.

The hyperactive child syndrome as it was originally conceived was thought to be a condition of childhood. Experienced clinicians could write: "In later years this syndrome tends to wane spontaneously and disappear. We have not seen it persist in those patients we have followed to adult life." ${ }^{\prime 6}$ This view was widespread and was formally acknowledged in DSM-II (1968). This perception was altered by the outcomes of prospective studies from Montreal $^{7}$ and New York. ${ }^{89}$ Weiss et al followed up 61 of an original cohort of 104 hyperactive children first seen between the ages of 6 and $12 .{ }^{7}$ At an average age of 25.1 years, $61 \%$ still reported features of restlessness, poor concentration, and impulsivity, compared with $7 \%$ of a matched control group. Twenty three per cent received a DSM-III diagnosis of antisocial personality disorder, against $2.5 \%$ in the control group.

Gittelman et al studied 101 white male children aged between 6 and 12 years who were deemed hyperactive. ${ }^{9}$ Subjects with comorbid conduct disorder were excluded. Nine years later $31 \%$ met DSM-III criteria for a diagnosis of attention deficit disorder with hyperactivity (a forerunner of $\mathrm{AD} / \mathrm{HD}$ ) - a diagnosis shared by only $3 \%$ of the control group. Twenty seven per cent and 16\% of the original cohort, respectively, received diagnoses of antisocial personality disorder and substance abuse, compared with $8 \%$ and $3 \%$ of the controls, but the excess was largely accounted for by those in whom the AD/HD symptoms had persisted. Drug abuse was accounted for almost exclusively by those with antisocial personality disorder.

In an extension of the cohort follow up period to 16 years, and thus into the middle of the third decade, ${ }^{9}$ the proportion meeting criteria for DSM-IIIR diagnosis of $\mathrm{AD} / \mathrm{HD}$ had fallen to $8 \%$, against $1 \%$ in the control group. The prevalence of antisocial personality disorder, though still excessive, had fallen and was no longer linked to the retention of the AD/HD diagnosis. The probands had completed fewer years of schooling and were of a lower socioeconomic status.

A community based study, ${ }^{10}$ which included some subjects who were comorbid for conduct disorder, was continued into late adolescence. The subjects who were comorbid for hyperactivity and conduct disorder had a higher prevalence of persistent $\mathrm{AD} / \mathrm{HD}$ $(29 \%)$ than those who had hyperactivity $(20 \%)$ or conduct disorder (11\%) alone; but if ICD-10 rather than DSM-IIIR criteria were used, the prevalence figures were approximately halved. Data from these prospective US and UK cohort series suggest that $\mathrm{AD} / \mathrm{HD}$ may persist into the third decade and probably beyond. The reported prevalence will vary according to selection criteria used-in particular, whether the study is community or clinic based, whether comorbid conduct disorder is included, and which classification system is used.

Relatively unbiased cross sectional data have only recently been reported. ${ }^{11}$ Applicants for driving licence renewal were invited to participate, and diagnosis was based on self report. Persistent $\mathrm{AD} / \mathrm{HD}$ symptoms were reported in $4.7 \%$, declining with age. Variables that might predict persistence of symptoms have received surprisingly little attention. Impulsivity/hyperactivity rather than inattention, and comorbidity for conduct disorder, each predict persistence, as does the presence of a family history of $\mathrm{AD} / \mathrm{HD}$.

\section{ASSESSMENT}

There are many pitfalls to the diagnostic process. There are no confirmatory laboratory based investigations. Clinical observations may be quantified by standardised instruments but ultimately diagnosis is a matter for clinical judgement. Even a positive response to treatment cannot be taken to provide unqualified support for the diagnosis, as cerebral stimulants may enhance cognitive functions, particularly those mediated by the prefrontal cortex, in normal volunteers. ${ }^{12}$ The diagnosis of childhood $\mathrm{AD} / \mathrm{HD}$ rests on relatively secure foundations. The child is constantly supervised, at home and in the school, and behavioural observations may be highly structured and detailed. The young adult frequently lives alone and is unemployed. Psychiatric illness in adults usually presents as a change in mental state, from normal to abnormal; the assessment of enduring characterological traits that have a dimensional rather than a categorical distribution is more challenging. The assessment of the adult who presents for the first time with possible $\mathrm{AD} / \mathrm{HD}$ features is considerably more difficult than the continuing evaluation of the patient in whom the diagnosis was made during childhood. The concept of adult AD/HD has received considerable media attention in the United Kingdom, but few clinicians feel competent to diagnose it. Ninety per cent of referrals to a specialist clinic were initiated by the patient or

Abbreviations: $A D / H D$, attention deficit hyperactivity disorder; DSM Diagnostic and Statistical Manual of Mental Disorders; ICD, International Classification of Diseases 
family, with the medical referer playing a passive rather than a gate keeping role. $^{13}$ The DSM-IV criteria are detailed and explicit and can be employed as a framework for a structured interview, using the $\mathrm{AD} / \mathrm{HD}$ portion of the adult interview ${ }^{14}$ in which the original wording has been adapted to adult usage. This is not without its limitations. The cardinal features of $\mathrm{AD} / \mathrm{HD}$ are ubiquitous in adult psychiatric practice, and the issue of symptom overlap has never been satisfactorily resolved. ${ }^{15}$ If consideration is given to the presentation and development of symptoms over time, a distinction can be more readily made. In a recent history of patients referred to a UK clinic, ${ }^{13}$ the majority sought a diagnosis of $\mathrm{AD} / \mathrm{HD}$ and were dissatisfied not to get it. The risk of self rater bias should not be underestimated. Disruptive childhood behaviour may have other explanations.

$\mathrm{AD} / \mathrm{HD}$ is a condition where the features are apparent, though not necessarily detected, during early childhood. It is essential when considering the diagnosis for the first time in adult life to remain cognisant of this and to seek confirmation, usually through a parental account of childhood behaviour, where possible supplemented by contemporaneous evidence-for example, school reports, educational psychology reports, and so on. Several rating scales have been devised in attempts to quantify childhood $\mathrm{AD} / \mathrm{HD}$ behavioural traits, such as Conner's abbreviated rating scale. ${ }^{16}$ These may be completed by the patient, but parental report is more reliable and should be sought wherever possible. Although quantitative psychometric testing may be used in the assessment of childhood $\mathrm{AD} / \mathrm{HD}$, its contribution as an aid to diagnosis has yet to be established. ${ }^{17}$ The position with adults is even less secure. Tasks such as the continuous performance test and the matching familiar figures test purportedly measure, respectively, sustained attention and impulsivity, but there is only limited and inconsistent evidence that they discriminate between $\mathrm{AD} / \mathrm{HD}$ subjects and normal controls, even less so other psychiatric disorders. Improvements in the continuous performance test following the introduction of methylphenidate ${ }^{18}$ and the Stroop test after the introduction of tomoxetine, a noradrenergic receptor inhibitor, ${ }^{19}$ have been reported, but most attempts to demonstrate treatment effects in psychometric performance have been unsuccessful. The tests that are currently used in the assessment of adult $\mathrm{AD} / \mathrm{HD}$ were not designed with that aim in mind; they are used because they are standardised tests that psychometrists are familiar with-hence their relatively poor discriminatory value.

\section{MANAGEMENT}

The most effective element in the management of $\mathrm{AD} / \mathrm{HD}$ is pharmacological. The recently published results of the multimodel treatment study of children with $\mathrm{AD} / \mathrm{HD}^{20}$ emphasise the essentially adjunctive role of psychosocial treatment. The treatment of the adult does not differ from that of the child other than in details such as the dose adjustment for greater body weight.

The class of drugs described as cerebral stimulants remains the cornerstone of drug treatment. Drugs of this class, of which methylphenidate and dexamphetamine are the most widely prescribed, act principally by blocking reuptake of monoamines, particularly dopamine and noradrenaline. Over a dozen controlled trials have now been conducted in adults and all but one showed a significant benefit from the active drug. ${ }^{21}$ The mean response rate of $60 \%$ across trials is less than in children $(60$ $70 \%)$ or adolescents $(75 \%)$. This may reflect the uncertainties of diagnosis, comorbidity, non-compliance, or poorly developed measures of responsiveness. It may also be a consequence of inadequate dosage: in one study a dose of $1 \mathrm{mg} / \mathrm{kg}$ body weight was adopted and a response rate of $78 \%$ reported..$^{22}$

There are few absolute contraindications to the use of cerebral stimulants in adults. These include the presence of psychotic symptoms or a history of substance abuse. It is best to treat comorbid conditions, particularly affective disorders, first, before proceeding to address $\mathrm{AD} / \mathrm{HD}$. Cerebral stimulants are well tolerated in adults. Sustained release preparations have been developed commercially and Concerta-the sustained release form of methylphenidate-is available in the United Kingdom, thus obviating the need for twice and thrice daily dosing.

The commonest symptoms in order of frequency of occurrence are: insomnia, edginess, diminished appetite, dysphoria, and headache. ${ }^{21}$ Most remit with time or a reduction in dosage. Psychosis has been reported in children but not adults. The potential for iatrogenic substance abuse exists, but has not been reported. Those patients who fail to respond to cerebral stimulants may respond to tricyclic antidepressants such as desipramine, ${ }^{23}$ tomoxetine, ${ }^{15}$ or venlafaxine. $^{24}$ Other drug treatments, for example the $\alpha 2 \mathrm{a}$ agonists such as clonidine and the $\beta$ blockers, have been used but their value is yet to be established. The selective serotonin reuptake inhibitors (SSRIs) have not been systematically evaluated in adults or in children, but there appears to be a consensual view based on clinical experience that they are ineffectual..$^{25}$ The more sedating neuroleptics may have a calming effect, but their side effects render them unsuitable for any role in the management of $\mathrm{AD} / \mathrm{HD}$.

It would seem that several different classes of drug may modify $\mathrm{AD} / \mathrm{HD}$ symptoms. It is not yet possible to locate a common site of action with any precision, but the more effective treatments act on monoaminergic pathways, notably those involving dopamine and noradrenaline. Behavioural, cognitive, and psycho-educational treatments play an important, if subsidiary, role in the management of childhood $\mathrm{AD} / \mathrm{HD} .^{20} \mathrm{~A}$ combination of drug treatment and behavioural strategies was superior to drug treatment alone. It would be surprising if the same were not also true of adults with $\mathrm{AD} / \mathrm{HD}$ but very little has been published on this.

\section{AETIOLOGY}

Although a precise understanding of the aetiology of $\mathrm{AD} / \mathrm{HD}$ remains elusive, the directions along which the inquiry should proceed have been clearly indicated. $\mathrm{AD} / \mathrm{HD}$ is known to aggregate within families, and twin studies that examine the relative importance of genetic and environmental influences have consistently shown an important genetic influence in childhood, with estimates of additive genetic variance of the order of $60-90 \%$. The risk to first degree relatives of probands with uncomplicated childhood $\mathrm{AD} / \mathrm{HD}$ is low (3.2\% for siblings; $5.6 \%$ for parents) but rises when $\mathrm{AD} / \mathrm{HD}$ is combined with conduct disorder or when it is persistent. In the presence of each additional risk factor the risk increases to $25.9 \%$ and $22 \%$, respectively. Studies in molecular genetics have adopted the candidate gene strategy, relying upon a specific gene hypothesis suggested by the known pathophysiology of $\mathrm{AD} / \mathrm{HD}$, rather than positional cloning, a hypothesis-free approach depending on genome scanning. Drug response outcomes and neuroimaging findings suggest abnormalities in the genetic regulation of monoamine neurotransmission, and molecular research has focused on this area. Two genetic associations (DRD4 and DAT1) replicate across multiple studies; in others (the serotonin $1 \mathrm{~B}$ receptor, the dopamine D5 receptor, and the synaptosomal associated ${ }^{25}$ ) the current evidence is less certain. The genetic contribution is likely to be one of multiple small effects: for example, one of the studies that confirm the significance of the DATl allele estimated that it explained only 
$3.6 \%$ of the variance in hyperactivity/ impulsivity symptoms and $1.1 \%$ in inattention symptoms.

How is the genetic contribution to $\mathrm{AD} / \mathrm{HD}$ mediated? A neurobiological model, albeit still somewhat hazy, is beginning to take shape. Much adult $\mathrm{ADH} / \mathrm{HD}$ symptomatology-for example, impaired organisational skills, weak impulse control-suggests executive dysfunction. The results of neuropsychological investigations are broadly consistent, but no more, with these clinical observations. Attentional measures such as the continuous performance test and the Stroop test reliably differentiate between $\mathrm{AD} / \mathrm{HD}$ subjects and normal controls, but not between $\mathrm{AD} / \mathrm{HD}$ subjects and psychiatric controls. ${ }^{26}$ The clear superiority of the cerebral stimulants over other classes of drugs implicates the monoaminergic system, particularly dopamine and noradrenaline. Structural imaging, more specifically cranial magnetic resonance imaging studies, have been consistent in demonstrating reduced area or volume of prefrontal, basal ganglia, and cerebellar vermis structures. (In childhood an $\mathrm{AD} / \mathrm{HD}$ syndrome may appear following severe closed head injury, ${ }^{27}$ particularly if the right putamen is involved. ${ }^{28}$ ) The outcomes of functional neuroimaging studies are less easily summarised, not least because of the multiplicity of imaging techniques and diverse methodology. Those studies that have used inhibitory paradigms-for example, the Gonogo ${ }^{29}$ and Stop ${ }^{30}$ tasks - find reduced or abnormal activation patterns in prefrontal and striatal structures. ${ }^{18}$ Fluorodopa was used to label catecholamine terminals to demonstrate a reduction in prefrontal areas in $\mathrm{AD} / \mathrm{HD}$ adults $^{31}$ and increase in midbrain in adolescents. ${ }^{32}$ These results, while not easy to piece together, lend support to the concept that catecholamine dysregulation is central to $\mathrm{AD} / \mathrm{HD}$ pathophysiology. There is certainly evidence to suggest that the therapeutic actions of the cerebral stimulants are located in the prefrontal cortex, and a prevailing view is that many $\mathrm{AD} / \mathrm{HD}$ symptoms may arise from insufficient catecholamine receptor stimulation in that region. This could arise in several ways-for example, reduced dopamine or noradrenaline prefrontal cortex innervation, presynaptic receptors that are overly responsive to dopamine, noradrenaline stimulation, and so on. The demonstration of increased binding of selected dopamine transporter ligands in $\mathrm{AD} / \mathrm{HD}$ adults ${ }^{33}{ }^{34}$ and the reduction in binding following treatment with methylphenidate, ${ }^{34}$ taken in conjunction with molecular genetic studies, provides an example of how catecholamine dysregulation can act, though it is highly unlikely that this occurs as a result of one dysfunctional locus. The probability is that, over time and perhaps through comprehensive genome mapping, multiple sites will be identified.

\section{J Neurol Neurosurg Psychiatry}

2004:75:523-525.

doi: 10.1136/jnnp.2002.002022

Correspondence to: Dr B Toone, King's College London, Denmark Hill, London SE5 9RS, UK; brian.toone@btinternet.com

\section{REFERENCES}

1 Sandberg S. Hyperkinetic or attention deficit disorder. Br J Psychiatry 1996;169:10-17.

2 WHO. Classification of mental and behavioural disorders: clinical descriptions and diagnostic guidelines. Geneva: World Health Organisation, guidelines.

3 Am Psychiatric Assoc. Diagnostic and statistical manual of mental disorders, 4th ed. Washington DC: American Psychiatric Association, 1994.

4 Taylor E, Sandberg S, Thorley G, et al. The epidemiology of childhood hyperactivity. New York: Oxford University Press, 1991.

5 Costello EJ, Costello AJ, Edelbrock C. Psychiatric disorder in paediatric primary care. Arch Gen Psychiatry 1988:1107-16.

6 Laufer M, Denhoff E. Hyperkinetic behaviour disorders in children. J Pediatr 1957:50:463-74.

7 Weiss G, Hechtman L, Milroy T, et al. Psychiatric status of hyperactives as adults: a controlled prospective 15-year follow-up of 63 hyperactive children. J Am Acad Child Psychiatry 1984;24:21 1-20.

8 Mannuzza S, Klein RG, Besslea A, et al. Adult outcome of hyperactive boys: educational achievement, occupational work, and psychiatric status. Arch Gen Psychiatry 1993:50:565-77.

9 Gittleman R, Mannuzza S, Shenker R, et al. Hyperactive boys almost grown up. Arch Gen Psychiatry 1985:42:937-47.

10 Taylor E, Chadwick O, Heptinstall U, et al. Hyperactivity and conduct problems as risk factors for adolescent development. J Am Acad Child Adolesc Psychiatry 1996;35:1213-26.

11 Murphy KR, Barkley RA. Attention deficit hyperactivity disorder in adults. Compr Psychiatry 1996:37:393-401.

12 Mehta MA, Sahakian BJ, Robbins W. Comparative psychopharmacology of methylphenidate and related drugs in human volunteers, patients with ADHD, and experimental animals. In: Solanto M, Arnsten A, Castellanos FX eds. Stimulant drugs and ADHD: basic clinical neuroscience. New York: Oxford University Press, 2001:303-31.

13 van der Linden G, Young S, Ryan P, et al. Attention deficit hyperactivity disorder in adults experience of the first National Health Service clinic in the United Kingdom. J Mental Health 2000;9:527-35.

14 Murphy KR, Gordon M. Assessment of adults with ADHD. In: Barkley RA, ed. Attention deficit hyperactivity disorder. New York: Guilford Press, 1998:345-69.

15 Shaffer D. Attention deficit hyperactivity disorder in adults. Am J Psychiatry 1994; 151:633-8.
16 Conners CK, Barkley RA. Rating scales and checklists for child psychopharmacology. Psychopharmacol Bull 1985:21:809-38.

17 Solanto MB. The predominantly inattentive subtype of attention-deficit/hyperactivity disorder. CNS Spectrums 2000;5:45-51.

18 Gualtieri CT, Ondrusek G, Finley C. Attention deficit disorders in adults. Clin Neuropharmacol 1985;4:343-56.

19 Spencer T, Biederman J, Wilens T, et al. Effectiveness and tolerability of tomoxetine in adults with attention deficit hyperactivity disorder. Am J Psychiatry 1998;155:693-5.

20 Jensen PS, Arnold LE, Richters JE, et al. A fourteen month randomised clinical trial of treatment strategies for attention-deficit/ hyperactivity disorder. Archives of Gen Psychiatry 1999;56:1073-1086.

21 Spencer T, Wilens D, Biederman J, et al. A double-blind, crossover comparison of methyl phenidate and placebo in adults of childhoodonset attention-deficit hyperactivity disorder. Arch Gen Psychiatry 1995;52:434-43.

22 Wilens TE, Spencer TJ. The stimulants revisited. Child Adolesc Psychiatr Clin North Am 2000;9:573-603.

23 Willens TE, Biederman J, Prince J, et al. Six-week, double-blind, placebo controlled study of desipramine for adult attention deficit hyperactivity disorder. Am J Psychiatry 1996:153:1 147-53.

24 Hedges D, Reimherr FW, Rogers A, et al. An open trial of venlafaxine in adult patients with Attention Deficit Hyperactivity Disorder. Psychopharmacol Bull 1995:31:779-83.

25 Pliszka S R. Comparing the effects of stimulant and non-stimulant agents on catecholamine function: implications for theories of ADHD. In: Solanto M, Arnsten A, Castellanos FX, eds. Stimulant drugs and ADHD: basic and clinical neuroscience. New York: Oxford University Press, 2001:332-54.

26 Woods SP, Lovejoy DW, Ball JD.

Neuropsychological characteristics of adults with ADHD: A comprehensive review of initial studies. Clin Neuropsychologist 2002;16:12-34.

27 Max JE, Arndt S, Castillo CSI. Attention-deficit hyperactivity symptomatology after traumatic brain injury: a prospective study. J Am Acad Child Adolesc Psychiatry 1998;37:841-7.

28 Herskovits EH, Megalooikononou V, Davatzikos C. Is the spatial distribution of brain lesions associated with closed-head injury predictive of subsequent development of attention deficit/hyperactivity disorder? Analysis with brain image database. Radiology 1999;213:389-94.

29 Vaidya CJ, Austin G, Kirkorian G, et al. Selective effects of methyl phenidate in attention deficit hyperactivity disorder: a functional magnetic resonance imaging study. Proc Natl Acad Sci USA 1998;95:14494-9.

30 Rubia K, Overmeyer S, Taylor E, et al. Hypofrontality in attention deficit hyperactivity disorder during higher order motor control: a study using fMRI. Am J Psychiatry 1999;156:891-6.

31 Ernst N, Zanetkin AJ, Matochik JA, et al. DOPA decarboxylase activity in attention deficit hyperactivity disorder in adults. A [fluorine-18] fluorodopa positron emission tomographic study J Neurosci 1998; 18:5901-7.

32 Ernst $\mathbf{N}$ Zanetkin AJ Matochik JA, et al. High midbrain ${ }^{18} \mathrm{~F}$-DOPA accumulation in children with ADHD. Am J Psychiatry 1999; 156:1209-15.

33 Dougherty DD, Bonab AA, Spencer TJ, et al Dopamine transporter density is elevated in patients with attention deficit hyperactivity disorder. Lancet 1999;354:2132-3.

34 Krause KH, Dresel SH, Krause J, et al. Increased striatal dopamine transporter in adult patients with attention deficit hyperactivity disorder: effects of methyl phenidate as measured by single photon emission computer tomography. Neurosci Lett 2000;285:107-10. 


\section{The MS symptom and impact diary (MSSID): psychometric evaluation of a new instrument to measure the day to day impact of multiple sclerosis}

\section{J G Beaumont}

\section{A welcome addition to the toolkit of those who work with multiple sclerosis}

n is a truism that multiple sclerosis is not only the most common of the neurodegenerative diseases but also the most variable in presentation and course. This is not only true of the relapsing-remitting form of the disease, where it is particularly evident, but it also applies to the rate of progression within progressive forms of the disorder. These characteristics of the disease pose problems for the clinical management of multiple sclerosis as well as for research into the pathology, treatment, and management of the disorder.

The multiple sclerosis symptom and impact diary (MSSID), reported in this issue, ${ }^{1}$ makes a significant addition to the tools available to the researcher and the clinician. The diary is a method by which day to day fluctuations in symptomatology, and their impact on daily life, can be recorded and assessed from the perspective of the patient's own experience. The MSSID has a carefully structured format which contributes to the strength of its psychometric properties, having two questions which address symptoms, five which assess impact, and one open ended question allowing any additional information to be reported. The two questions that inquire about symptoms require, first, a binary decision about the presence of 14 symptom areas "today"; and second a rating of the interference which they produced (although the psychometric analysis indicates that this is treated by respondents as "severity" as well as "impact"). The next five questions require more global five or six point ratings of the impact of the disorder. The practised user can no doubt complete the daily diary entry quickly and easily.

The authors of the MSSID have conducted a thorough and appropriate statistical analysis of the properties of the instrument, which is to be welcomed in a field where such questionnaires are not always so carefully constructed. In their study of 63 outpatient clinic attenders, internal reliability was found to be good, and testretest reliability acceptable, given that the MSSID retains the ability to record changes which occur on a daily basis. Validity is inevitably a methodologically thorny issue when individual centred instruments are being considered, and in a wholly idiographic questionnaire validity can strictly never be determined. However, the authors demonstrate that the MSSID possesses good discriminant validity, with the expected differences being observed among clinical multiple sclerosis subgroups. Convergent validity is a more questionable approach, but the finding of "moderate" correlations with several cognate measures is what reasonably might be expected.

The relation and differences between the MSSID and other similar measures are what will also determine its usefulness. Before and after the 12 week study, participants also completed an MS-specific measure of quality of life $\left(\mathrm{LMSQoL}^{2}\right)$, a measure of health status $\left(\mathrm{MSQOL}^{-54^{3}}{ }^{3}\right.$, a measure of functional ability (Barthel index ${ }^{4}$ ), the London handicap scale $\left(\mathrm{LHS}^{5}\right)$, and the reintegration to normal living index $\left(\mathrm{RNLI}^{6}\right)$, the two latter being measures of participation and handicap. None of these is suitable for daily completion, given their length or their likely responsiveness to short term variations in symptoms. The relations between the factors identified in the MSSID and these measures was typically a correlation in the region 0.3 to 0.5 , so there is roughly only $10 \%$ to $25 \%$ of common variance in what is being recorded. This no doubt partly reflects the differing levels of responsiveness of instruments and, more simply, the fact that rather different questions are asked, but it also relates MSSID and the fact that patients' perceptions of their condition are to the individual centred nature of the affected by a range of psychological factors which interact with the "objective" physiological state of the disease. Ample research has shown that individuals' perceptions of their symptoms and the personal impact of their disease are not fully concordant with objectively recorded health status (see, for example, Murrell et $\mathrm{al}^{7}$ in relation to multiple sclerosis). Neither is more valid than the other; they are related but different phenomena with differing health care implications. It is important to recognise that the MSSID provides an individual based evaluation but gives little valid information to the clinician or researcher about the daily medical status of the respondent.

The closest "competitor" to the MSSID must be the multiple sclerosis impact scale $\left(\right.$ MSIS-29 $\left.{ }^{8}\right)$. This scale, validated on three samples totalling 233 individuals with multiple sclerosis, has 29 simple questions, each requiring a rating on a five point scale. In terms of the demands placed upon respondents and the cognitive ability required to complete it, it differs little from the MSSID. The psychometrics of the scale have not been as extensively analysed, but it has been shown to possess good reliability and validity to an approximately equal degree. The principal difference is that the MSIS-29 specifically requires respondents to consider the impact of their disease "in the past two weeks," and so cannot record the day to day variability which is the focus of the MSSID. Potential users will decide which is the more appropriate questionnaire for their purposes.

The authors acknowledge that their study was only concerned with clinic attenders who were volunteers. The very good results with this group are encouraging for what is likely to be one of the more important applications of the MSSID-in drug studies. An earlier version of the MSSID was, in fact, developed for just this application. Nonetheless, various other applications are suggested by the authors, in a variety of research contexts and in clinical reporting, providing that the response rate and consistency of completion is maintained in community samples and in those who are not so motivated by a desire to advance medical knowledge. This remains to be seen. The MSSID is simple and brief enough to be applicable to all but the most severely affected multiple sclerosis sufferers, completion being possible at all levels until communication becomes profoundly impaired, with assistance in recording if required.

There is a final concern that has not been considered by the authors-the possible psychological impact of daily 
evaluation of symptoms upon the respondents. Although people with multiple sclerosis are in any event generally very aware of their changing symptoms, the regular evaluation and recording of these symptoms and their impact will not only have an effect on the perception of the symptoms themselves, but could also have an adverse effect upon the psychological adjustment of the respondent. There is an ethical issue here which deserves further consideration and evaluation. Nevertheless, the MSSID is a welcome addition to the toolkit of those who work, either clinically or in a research context, with individuals with multiple sclerosis.
$J$ Neurol Neurosurg Psychiatry 2004;75:526-527.

doi: 10.1136/jnnp.2003.032367

Correspondence to: Professor J G Beaumont, Department of Clinical Psychology, Royal Hospital for Neuro-disability, West Hill, Putney, London SW15 3SW, UK;

gbeaumont@rhn.org.uk

\section{REFERENCES}

1 Greenhalgh $\mathrm{H}$, Ford $\mathrm{H}$, Long AF, et al. The MS Symptom and Impact Diary (MSSID):

Psychometric evaluation of a new instrument to measure the day-to-day impact of multiple sclerosis. I Neurol Neurosurg Psychiatry 2004; 75:577-82

2 Ford HL, Gerry E, Tennant A, et al. Developing a disease-specific quality of life measure for people with multiple sclerosis. Clin Rehabil 2001;15:247-58.
3 Vickrey BG, Hays RD, Harooni M, et al. A healthrelated quality of life measure for multiple sclerosis. Qual Life Res 1995;4:187-206.

4 Mahoney Fl, Barthel DW. Functional evaluation: the Barthel index. Maryland State Med J 1965;14:61-5.

5 Harwood RH, Rogers A, Dickinson E, et al. Measuring handicap: the London Handicap Scale, a new outcome measure for chronic disease. Qual Health Care 1994;3:11-16.

6 Wood-Dauphinee S, Opzoomer MA, Williams JI, et al. Assessment of global function: the Reintegration to Normal Living index. Arch Phys Med Rehabil 1987;69:583-90.

7 Murrell RC, Kenealy PM, Beaumont JG, et al. Assessing quality of life in persons with severe neurological disability associated with multiple sclerosis: the psychometric evaluation of two quality of life measures. Br J Health Psychol 1999:4:349-62.

8 Riazi A, Hobart JC, Lamping DL, et al. The Multiple Sclerosis Impact Scale (MSIS-29): reliability and validity in hospital based samples. J Neurol Neurosurg Psychiatry 2002;73:701-4.

\section{Grey hair and grey matter}

\section{L van de Pol, P Scheltens}

\section{Could treating memory disorders prevent dementia?}

$M$ emory complaints are very common in elderly people. In 1958 $\mathrm{Kral}^{1}$ had already introduced the terms "benign and malignant senescent forgetfulness," attempting to differentiate between "normal" and pathological decline in memory performance during aging. Since that time the discussion has been continuing and many definitions for a suspected "transitional" stage between normal aging and dementia have been proposed. In the currently widely used criteria of "mild cognitive impairment" (MCI) by Petersen et $a l^{2}$ one of the five key elements is objective memory impairment on testing, corrected for age and education, suggesting that age has an influence on memory performance. Yet little is known about the cognitive and structural changes that occur in the normal brain with aging. The study by Lyle et al in this issue tries to define magnetic resonance imaging (MRI) correlates of normal brain aging. ${ }^{3}$

The investigators carried out cranial MRI in 102 very old community dwelling individuals (aged 82 to 94 years). Using a multivariate model with hippocampal size, estimated visually and volumetrically, sociodemographic factors, and age related disease as predictors of memory performance, they found that left hippocampal measurements were predictive, especially on delayed retention of verbal material. Even in a subgroup of cognitively healthy elderly people (clinical dementia rating $(\mathrm{CDR})=0)$, left hippocampal measures remained predictive of delayed retention of verbal information. For those fond of visual rating of hippocampal atrophy, the results support the view that visual and volumetric estimates of hippocampal size perform equally well. ${ }^{4}$

These results strengthen the already widely known relation between the hippocampus and memory, but what do they tell us about (normal) aging? When comparing the cognitively healthy group $(n=57)$ with the group as a whole, the difference in influence of age on memory is striking. Age was a significant predictive factor in memory performance in the group as a whole, but lost its predictive value in the cognitively healthy group. In the light of this, is it possible that (a part of) the subgroup of $\mathrm{CDR} \geqslant 0.5$ was mildly demented, and although these subjects were selected from the community, can they still be regarded as representatives of "normal" aging? If not, this might be considered an indication that age predicts memory deficits through the age related presence of hippocampal pathology. In this respect it would have been interesting to compare hippocampal sizes between the two groups. It has been shown repeatedly that hippocampal atrophy is a sensitive marker of early Alzheimer's disease pathology. Jack et al have observed a decline in volume of all medial temporal lobe structures, including the hippocampus, with advancing age, and were able to discriminate normal aging from early dementia among subjects with a CDR of 0.5. ${ }^{5}$

Studies correlating MRI and pathology in the very old are much needed. Hippocampal atrophy may be sensitive to Alzheimer's disease ${ }^{6}$ but lacks specificity, and the pathological basis of radiologically observed hippocampal atrophy in normal aging is still largely unknown. It seems reasonable to assume that besides Alzheimer's disease pathology there may be other processes in aging that target the hippocampus, such as hippocampal sclerosis or vascular damage.

A better understanding of the basic mechanisms of cognitive function and its anatomical correlates in normal brain aging will help clinicians to diagnose and treat memory disorders in the elderly and possibly to prevent dementia as the ultimate consequence of longevity. ${ }^{7}$

J Neurol Neurosurg Psychiatry 2004; 75:527-528.

doi: 10.1136/jnnp.2003.032391

\section{Authors' affiliations}

L van de Pol, P Scheltens, Alzheimer Centre and Department of Neurology, Vrije

Universiteit Medical Centre, PO Box 7057

Amsterdam, Netherlands

Correspondence to: Professor Philip Scheltens; p.scheltens@vumc.nl

\section{REFERENCES}

1 Kral VA. Senescent forgetfulness: benign and malignant. Can Med Assoc J 1962;86:257-60. 
2 Petersen RC, Doody R, Kurz A, et al. Current concepts in mild cognitive impairment. Arch Neurol 2001;58:1985-92.

3 Lye TC, Piguet O, Grayson DA, et al. Hippocampal size and memory function in the ninth and tenth decades of life: the Sydney Older Persons Study. J Neurol Neurosurg Psychiatry 2004;75:548-54.
4 Wahlund LO, Julin P, Lindqvist J, et al. Visual rating and volumetry of the medial temporal lobe on magnetic resonance imaging in dementia. A comparative study. J Neurol Neurosurg Psychiatry 2000;69: 630-5.

5 Jack CR, Petersen RC, Xu YC, et al. Medial temporal atrophy on MRI in normal aging and very mild Alzheimer's disease. Neurology 1997;49:786-94

6 Scheltens $P$, Fox N, Barkhof $F$, et al. Structural magnetic resonance imaging in the practical assessment of dementia: beyond exclusion. Lancet Neurology 2002;1:13-21.

7 Drachman DA. If we live long enough, will we all be demented? Neurology 1994;44:1563-5.

CSF analysis in subarachnoid haemorrhage

\section{Recommendations for CSF analysis in subarachnoid haemorrhage}

\section{$R$ Beetham, on behalf of UK NEQAS For Immunochemistry Working Group*}

\section{Spectrophotometry of CSF involving bilirubin quantitation is the recommended method of analysis}

n

$\mathrm{n}$ this journal in the late 1980s, two papers presented contrasting advice about the appropriate investigation of cerebrospinal fluid (CSF) in suspected subarachnoid haemorrhage when computed tomography (CT) of the head revealed no evidence of blood. The first concluded that it was the detection of red blood cells that was important in supporting a decision to proceed to cerebral angiography and not that of the red cell breakdown products, oxyhaemoglobin and bilirubin. ${ }^{1}$ This was a conclusion based on the use of visual inspection to detect the colour (xanthochromia) imparted by oxyhaemoglobin and bilirubin. The second, based on a series of 111 patients in whom blood was found on CT, concluded that it was the presence of oxyhaemoglobin and bilirubin, as detected spectrophotometrically, that was important. ${ }^{2}$ An editorial in The Lancet picked on the difference in examination principle (visual inspection versus spectrophotometry) as being fundamental to the contrasting conclusions. ${ }^{3}$ The editorial concluded that spectrophotometry was the appropriate way in which to examine CSF when the occurrence of subarachnoid haemorrhage was in doubt. As was subsequently pointed out, the criteria recommended to determine a

${ }^{*}$ Members of Working Group: R Beetham (Chair), MN Fahie-Wilson, I Holbrook, ID Watson, PR Wenham, PAE White, P Thomas, AM Ward, A Cruikshank, G Keir, W Egner, K Allen. positive finding were ambiguous on two counts, and it was not clear that the conclusions reached from a study of patients where blood was detected could be extrapolated to those where blood was not visualised on imaging. ${ }^{4}$ Moreover, although the subjectivity involved in visual inspection of CSF had been replaced by spectrophotometry, this still involved a subjective interpretation of the spectrophotometric scan without any guidance on what quantitative amounts of oxyhaemoglobin or bilirubin constituted a positive finding.

Against this background it was clear that even in the late 1990s there was much confusion about how CSF should be analysed and the results interpreted in CT negative suspected subarachnoid haemorrhage. Consequently, a working group convened to produce guidelines on CSF sampling, transport, handling, analysis, and interpretation. Central to this process was a retrospective multicentre review of over 700 cases where spectrophotometry had been undertaken, haem pigments identified, and bilirubin quantitated, and where the angiographic outcome was known in 87 cases. While recognising the limitations of such a process, which inevitably would have resulted in some patient selection and population bias, this was a significant improvement on the knowledge that existed at this time.

These guidelines have now been published..$^{5}$ The key recommendations are as follows:
- Spectrophotometry of CSF involving bilirubin quantitation is the recommended method of analysis.

- This should be done on the final bottle of CSF to be collected.

- An increased CSF bilirubin is the key finding which supports the need for further investigation. Bilirubin will usually be accompanied by oxyhaemoglobin.

- The occurrence of oxyhaemoglobin alone is most often artefactual, but occasionally may occur with subarachnoid haemorrhage.

- Absence of oxyhaemoglobin and bilirubin on spectrophotometry is not supportive of subarachnoid haemorrhage.

In addition, the group has worked closely with UK NEQAS for Immunochemistry to produce a robust external quality assurance (EQA) scheme through which laboratories can maintain appropriate analytical and interpretative standards.

We believe that the production of the guidelines and the introduction of the EQA scheme represent a significant step forward in ensuring an appropriate standard of CSF analysis. We urge all clinicians and laboratories to adopt these practices.

J Neurol Neurosurg Psychiatry 2004;75:528. doi: 10.1136/jnnp.2003.023176

Correspondence to: Dr R Beetham, Department of Clinical Biochemistry, North Bristol NHS

Trust, Frenchay Hospital, Bristol BS16 1LE, UK; Robert.Beetham@north-bristol.swest.nhs.uk

\section{REFERENCES}

1 MacDonald A, Mendelow AD. Xanthochromia revisited: a re-evaluation of lumbar puncture and CT scanning in the diagnosis of subarachnoid haemorrhage. J Neurol Neurosurg Psychiatry 1988;51:342-4

2 Vermeulen $M$, Hassan D, Blijenberg BG et al. Xanthochromia after subarachnoid haemorrhage needs no revisitation. J Neurol Neurosurg Psychiatry 1989;52:826-8.

3 Editorial. Xanthochromia. Lancet 1989;ii:658-9.

4 Beetham R, Fahie-Wilson MN, Park D. What is the role of CSF spectrophotometry in the diagnosis of subarachnoid haemorrhage? Ann Clin Biochem 1998;35:1-4.

5 National guidelines for analysis of cerebrospinal fluid for bilirubin in suspected subarachnoid haemorrhage. A Working Group of UK NEQAS for Immunochemistry. Ann Clin Biochem 2003;40:481-8 